\title{
Antidiabetic effect of Polyherbal Formulation "Kathakakhadiradi Kashyam" in Streptozotocin induced Diabetic rats
}

\author{
Abdul Azeez, Shawn Tomy”, Faisal Mohamed Ali Abdalla, R Suresh, Benito Johnson \\ Dr MGR Medical University, Tamil Nadu Chennai, INDIA.
}

\begin{abstract}
Aim: The aim of the present study was to evaluate the antidiabetic potential of "kathakakhadiradi kashyam" (KKS) an indigenious polyherbal ayurvedic formulation in streptozotocin induced diabetes rat model. Methodology: Initially a single day oral glucose tolerance test was conducted and the effective dose $(1.08 \mathrm{ml} / \mathrm{kg})$ found in this study was taken for further evaluation in the 28 day continues administration study. The effects were compared with diabetic control and standard control groups. Result and Conclusion: The ratio of percentage reduction observed between standard drug treated group (Glibenclamide) and KKS treated group from the $7^{\text {th }}$ day to $14^{\text {th }}, 21^{\text {st }}$ and $28^{\text {th }}$ day are $43.99: 35.54,46.53: 44.4,53.88: 43.5$ respectively. When compared with all other groups KKS treated group shows more similar glucose lowering activities. The study also correlates food, water intake and body weight changes in different groups throughout the study. The results shows that KSS posses promising antidiabetic activity. More detailed
\end{abstract}

molecular level studies and toxicological evaluations are necessary to conform the safety and efficacy of KKS for clinical practice.

Key words: Kathakakhadiradi kashyam, Polyherbal, Antidiabetic activity, Oral glucose tolerance test.

\section{Correspondence :}

Shawn Tomy,

Pharm. D intern, Department of Pharmacy Practice, RVS College of Pharmaceutical Sciences,

Phone no: +918122472770

E-mail: shawn.kandathil1@gmail.com

DOI: 10.5530/jyp.2016.4.30

\section{INTRODUCTION}

Diabetes mellitus describes a metabolic disorder of multiple etiologies characterized by insulin resistance, relative insulin deficiency and hyperglycemia with disturbances of carbohydrate, fat and protein metabolism. The shift from the predominantly diurnal standard of living of our ancestors to unhealthy diet habits, physical inactivity and other aspects of lifestyle in developing countries has a major share in the growing incidence of Type 2 diabetes which accounts for about $90 \%$ of all cases at a younger age. India is one among the leading country with highest number of diabetic population with a current figure of 40.9 million, followed by China, USA, Russia, Germany, Japan, Pakistan, Brazil, Mexico and Egypt. The aetiology of diabetes in India is multifactorial and includes genetic factors coupled with environmental influences such as obesity associated with rising living standards, steady urban migration, and lifestyle changes. It is predicted that by 2030 diabetes mellitus may afflict up to 79.4 million individuals in India. Diabetes has become a serious health problem with continuously increasing rates of incidence and mortality. ${ }^{1}$ It is one of the refractory diseases identified by Indian council of medical research for which an alternative medicine is a need for the treatment.

The management of diabetes mellitus is considered a global problem and successful treatment is yet to be discovered. Even though the synthetic drugs, including insulin and oral hypoglycemic agents, control the blood sugar level as long as they are regularly administered, Cost, Complications, limited tolerability and other side effects reduces its wide acceptance. This situation may be the main reason for the shift of common people form allopathic system to ayurveda nowadays.

Traditional medicines all over the world have advocated the use of herbs to treat diabetes since time immemorial. Ayurveda is one of the traditional medicinal systems with an established history of many centuries. Furthermore known as Ayurvedic Medicine, this ancient Vedic knowledge is considered to be one of the oldest healing sciences and has survived until the present generation over many centuries of tradition. Originated in India thousands of years ago, Ayurveda is known as the "Mother of All Healing". In the Ayurvedic system of medicine, as mentioned in ancient Indian books like Charak, Samhita, Mahdhav Nidan and Astang Sanghra, there are about 600 plants, which are stated to have antidiabetic property. ${ }^{3}$ Wide arrays of plant derived active principles representing numerous phytochemicals have demonstrated consistent hypoglycemic activity and their possible use in the treatment of diabetes mellitus. Indian plants which are most effective and commonly studied in relation to diabetes and its associated complications are: Allium cepa, Allium sativum, Aloevera, Cajanus cajan, Coccinia indica, Caesalpinia bonducella, Ficus bengalenesis, Gymnema sylvestre, Momordica charantia, Ocimum sanctum, Pterocarpus marsupium, Swertia chirayita, Syzigium cumini, Tinospora cordifolia, graecum and Trigonella foenum. ${ }^{4}$ Even though more than 12000 plants have been described to be experimentally or ethnopharmacologically used in the treatment of diabetes, most of them lack in scientific validation. ${ }^{5}$

"Kathakakhadiradi kashyam" is an ayurvedic medicinal preparation which is widely used in the effective management of diabetes and maintaining associated symptoms such as polyuria, fatigue, constipation, dryness of mouth, polydipsia and excessive swetting. It can also be used against diabetic carbuncles and infections. Normal human dose ranges from 10-15 ml twice a day before food. The formulation also claims to have effects on urinary problems and immunity. Scientific data regarding the anti-diabetic effect of kathakakhadiradi kashyam is lacking hence the present study aims in evaluating the primary level anti diabetic potential of the same.

\section{MATERIALS AND METHODS CHEMICALS AND DRUGS}

Kathakakhadiradi kashyam was procured from the drug store of Ayurveda College, Coimbatore (AVP Ayurveda Pharmaceuticals). All the chemicals and reagents used in the study are of analytical grade.

\section{ANIMALS}

Healthy Albinorats of either sex of 2-21/2-months-old of body weight $125-150 \mathrm{~g}$ were housed in polypropylene cages at $25 \pm 2^{\circ} \mathrm{C}$ with light 
dark cycle of 12 hours in the Animal house of RVS College of Pharmaceutical Sciences (Registration No. 1012/c/06/CPCSEA). All the test animals were acclimatized for seven days and were given standard rat feed and water ad libitum. ${ }^{6}$ The experiments were performed after approval of the protocol by the Institutional Animal Ethics Committee (IAEC) and animal care was taken as per the guidelines of Committee for the Purpose of Control and Supervision of Experiments on Animals (CPCSEA), Government of India.

\section{INDUCTION OF DIABETES}

Experimental diabetes was induced by single i.p. injection of $60 \mathrm{mg} / \mathrm{kg}$ of streptozotocin (STZ), freshly dissolved in cold citrate buffer ( $\mathrm{pH} 4.5$ ) after $15 \mathrm{~min}$ of i.p. injection of nicotinamide $(110 \mathrm{mg} / \mathrm{kg})$ prepared in normal saline. Rats with marked glycosuria (fasting blood glucose level greater than $200 \mathrm{mg} / \mathrm{dL}$ ) after one week of administration of STZ were used for the study. ${ }^{7}$

\section{ORAL GLUCOSE TOLERANCE TEST (NORMAL RATS)}

Glucose is the main source of energy in ourbody, Oral Glucose Tolerance test (OGTT) measures the body's ability to use glucose effectively. Albino rats of either sex weighing 130-180 g were taken for the study. The rats were kept fasting overnight with free access to water. During experiment the animals were divided into three groups of six animals in each group. The blood samples were taken by tail vein pricking method. The formulation was administered using an oro-gastric tube.

Group I: Negative control- Treated with normal saline.

Group II: Standard group- Treated with standard oral hypoglycemic drug, i.e., Glibenclamide $(0.5 \mathrm{mg} / \mathrm{kg})$

Group III: Test- Treated orally with polyherbal preparation - KKS 0.54 $\mathrm{ml} / \mathrm{kg}$

Group IV: Test- Treated orally with polyherbal preparation - KKS 1.08 $\mathrm{ml} / \mathrm{kg}$

Group V: Test- Treated orally with polyherbal preparation - KKS 2.16 $\mathrm{ml} / \mathrm{kg}$

The dose of the formulation was calculated by extrapolating the therapeutic dose to rat dose on the basis of body surface area ratio (average human dose of Kathakakhadiradi kashyam is $12 \mathrm{ml}) .^{8}$ After 30 minutes to prior administration of normal saline, Glibenclamide and test drug to the animals in respective groups, $2 \mathrm{~g} / \mathrm{kg}$ body weight of glucose dissolved in distilled water were administered to all the animals. The blood glucose levels were determined using a glucometre (glucose oxidase method) at $0,0.5,1,2,3$ and $4^{\text {th }}$ hour of glucose administer. Blood sample for biochemical analysis were collected from tail vain. ${ }^{9}$

\section{HYPOGLYCAEMIC ACTIVITY}

Based on the results of OGTT results we proceed with 28 day hypoglycaemic activity study. A total of 18 diabetic and 6 non diabetic rats were randomly selected for the study (4 groups of 6 animals each)

Group I: $\quad$ Normal control - non diabetic + Normal saline

Group II: Diabetic control- Diabetic + Normal saline

Group III: Standard group- Diabetic + Glibenclamide (5 mg/kg)

Group IV: Test group-Diabetic + Kathakakhadiradi kashyam $(1.08 \mathrm{ml} / \mathrm{kg})$

Both glibenclamide and Kathakakhadiradi kashyam were administered orally using an oro-gastric tube once daily for 28 days. During the study animals were assessed for the following parameters:
The blood glucose levels were determined by the glucose oxidase method using glucometer (Accucheck active). ${ }^{10}$

\section{STATISTICAL ANALYSIS}

All values are expressed as mean \pm SEM. Statistical analysis was performed by One-way Anova followed by Dunnet's t-test using SPSS version 17. A 'p' value less than 0.05 was considered significant.

\section{RESULTS AND DISCUSSION}

KKS is a well established and widely used polyherbal kashyam used in the treatment of diabetes in ayurvedic system of medicine. The present study was an attempt to conform the anti diabetic potential of the same, were in we have used streptozotocin induced Type 2 diabetic model. Streptozotocin induced type 2 diabetic model is a widely used and validated animal model as the induced diabetic condition has close resemblance to that in humans.

\begin{tabular}{|c|c|}
\hline Parameters & Time interval \\
\hline Blood glucose & $0,7,14,21,28^{\text {th }}$ day \\
\hline Food intake & Daily \\
\hline Water intake & Daily \\
\hline Body weight & Weekly Once \\
\hline
\end{tabular}

Streptozotocin is a naturally occurring nitrosourea product of Streptomyces achromogenes, which is a potent DNA methylating agent and acts as a nitric oxide donor in pancreatic cells. The pancreatic $\beta$ cells are particularly sensitive to damage by nitric oxide and free radicals because of their low levels of free radical scavenging enzymes. STZ causes alkylation or breakage of DNA strands and a consequent increase in the activity of poly-ADP-ribose synthetase, an enzyme depleting NAD in beta cells finally leading to energy deprivation and death of beta cells.

Oral glucose tolerance test is a single day single administration test to find the effect of loaded glucose on blood glucose in KKS administered, standard drug administered and control group (vehicle administered) animals. Oral glucose tolerance test result shows a dose dependant blood glucose reducing nature of KKS on glucose loaded non diabetic rats (Figure 1). More significant reduction was exposed at doses 1.08 and $2.16 \mathrm{ml} / \mathrm{kg}$ doses. Comparing to standard anti diabetic drug (glibenclamide $5 \mathrm{mg} / \mathrm{kg}$ ) more activity was shown by KKS when administered at a dose of $2.16 \mathrm{ml} / \mathrm{kg}$ dose. Thus the average effective dose level observed $(1.08 \mathrm{ml} / \mathrm{kg})$ was fixed for the next level studies.Even though the graph shows scattered plotting pattern, at $2^{\text {nd }}$ hour and the $3^{\text {rd }}$ hour they shows similar readings at all the different concentrations.

More promising and reproducible results were shown by KKS during the 28 day uninterrupted administration studies. Table 1 shows the complete statistical image of the same. The reports obtained on the $7^{\text {th }}$ day of administer of KKS (260.8) was not so hopeful when compared to that of standard regimen $(267.8 \pm 3.15)$. But a more effective and significant reduction was shown by KKS on $14^{\text {th }}, 21^{\text {st }}$ and $28^{\text {th }}$ day $(168.1 \pm 1.22,145 \pm$ $2.2,148 \pm 4.7)$. KKS also exhibits the similar pattern of reduction lagging in the first week as almost all the ayurvedic and herbal formulations shows. The result scientifically proves that KKS has similar anti diabetic potential to that of standard marketed oral hypoglycaemic agent (Glibenclamide).

The ratio of percentage reduction observed between standard drug treated group (Glibenclamide) and KKS treated group from the $7^{\text {th }}$ day to $14^{\text {th }}$, $21^{\text {st }}$ and $28^{\text {th }}$ day are $43.99: 35.54,46.53: 44.4,53.88: 43.5$ respectively. In 
Azeez et al.: Antidiabetic effect of polyherbal formulation

Table 2: Represents the effect of KKS and Glibenclamide on STZ induced diabetic animals

\begin{tabular}{cccccc}
\hline & \multicolumn{5}{c}{ Serum Glucose Level } \\
\cline { 2 - 6 } Treatment & Initial & $\mathbf{7}^{\text {th }}$ day & $\mathbf{1 4}^{\text {th }}$ day & $\mathbf{2 1}^{\text {st }}$ day & $\mathbf{2 8}^{\text {th }}$ day \\
\hline Normal control & $90.97 \pm 1.47$ & $94.97 \pm 1.47$ & $104.3 \pm 4.1$ & $102 \pm 2.13$ & $89.52 \pm 2.16$ \\
Diabetic control & $104.22 \pm 0.22$ & $259.3 \pm 3.51$ & $303.2 \pm 5.5$ & $375.1 \pm 1.3$ & $405.3 \pm 1.26$ \\
Diabetic+Glibenclamide $(5 \mathrm{mg} / \mathrm{kg})$ & $104.12 \pm 1.2$ & $267.8 \pm 3.15^{* *}$ & $150.1 \pm 1.4^{* * *}$ & $143.2 \pm 0.5^{* * *}$ & $123.5 \pm 1.0^{* * *}$ \\
Diabetic+KKS $1.08 \mathrm{ml} / \mathrm{kg}$ & $94.1 \pm 5.5^{* *}$ & 260.8 & $168.1 \pm 1.22^{* * *}$ & $145 \pm 2.2^{* * *}$ & $148 \pm 4.7^{* * *}$ \\
\hline
\end{tabular}

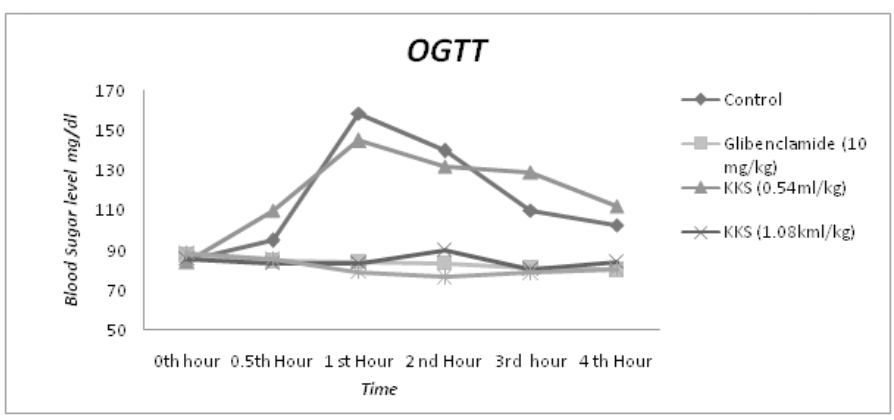

Figure 1: Represents the effect of oral glucose tolerance test on normal, vehice treated diabetic, glibenclamide treated diabetic and differents concentrations of KKS treated diabetic animals.

a similar study where an indigenous polyherbal preparation named Diakure when analysed shows a similar pattern of activity. GL (10 mg/ $\mathrm{kg}$ body wt) and Diakure $300 \mathrm{mg} / \mathrm{kg}$ treated rats showed a reduction in glucose by $7.1 \%, 45.5 \%, 50.1,53.9 \%$; and $12.3 \%, 33.3 \%, 49.5 \%, 59.7 \%$ on $7^{\text {th }}, 14^{\text {th }}, 21^{\text {st }}$, and $28^{\text {th }}$ day of the study $y^{6}$.

In an earlier study we could find that the KKS is rich in phytoconstituents like carbohydrates, proteins, amino acids, flavanoids, saponins, phenols and tannins. ${ }^{11}$ The combined or individual activities of these constituents may be the reason for the anti diabetic potential of the formulation.

The study also explored whether the blood glucose lowering effect was due to reduction of food intake, this was done by comparing the foo $\mathrm{d}$ intake between the diabetic control and formulation treated groups. The reports shows there is an increase in food and water intake in diabetic control group and a considerable change in this pattern was observed in both KKS as well as Glibenclamide treated group. This reports conforms the prediction that KKS could reduce polydipsia and polyphagia to a greater extent.The findings also suggest that the formulation does not alter normal metabolic parameters like food and water intake. Figure 2

\section{EFFECT OF KKS ON F OOD CONSUMPTION}

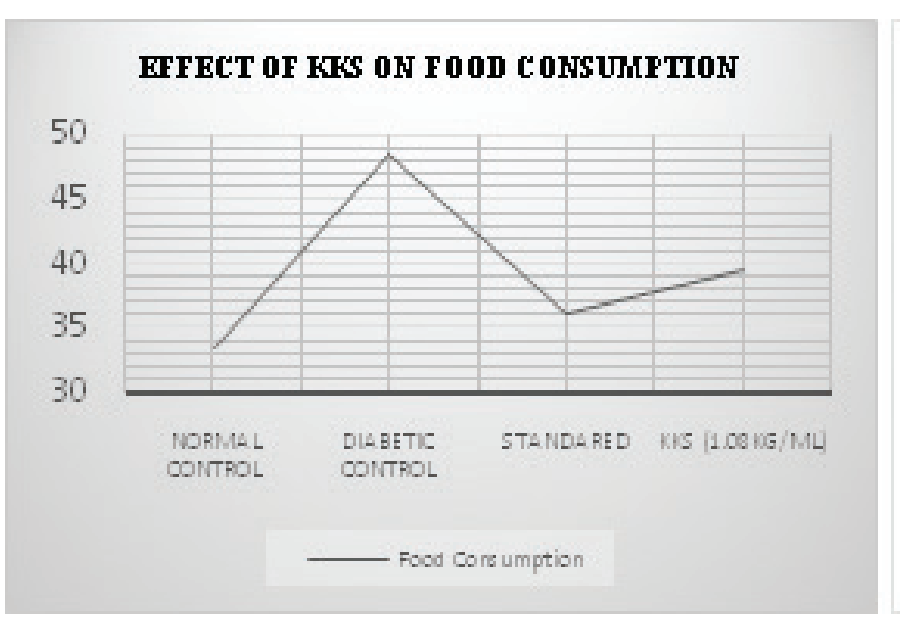

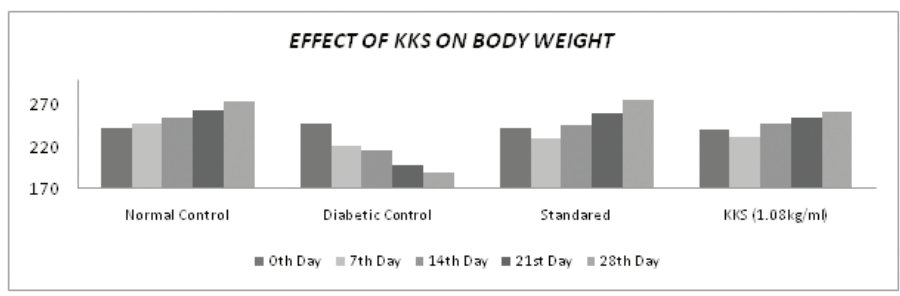

Figure 4: Represents the effect of body weight in different individual groups during the study

and 3 shows the effect of KKS, Glibenclamide and vehicle on food and water intake of animals during the 28 day study.

Figure 4 represents the body weight changes occurred during the study on all individual groups. The characteristic loss of bodyweight in diabetic control group is due to increased muscle wasting in diabetes. The increased muscle wastage may be due to reduced collagen synthesis and altered total protein balance in the body. ${ }^{12}$ A reversal of weight loss was observed in formulation treated group as well as glibenclamide treated group during the study.

The anti diabetic activity of herbs depends upon variety of mechanisms. The mechanism of action of the preparation may be by adrenomimeticism, pancreatic beta cell potassium channel blocking, cAMP $\left(2^{\text {nd }}\right.$ messenger) stimulation, inhibition in renal glucose reabsorption, stimulation of insulin secretion from beta cells of islets or/and inhibition of insulin degradative processes, reduction in insulin resistance, providing certain necessary elements like calcium, zinc, magnesium, manganese and copper for the beta-cells, regenerating and/or repairing pancreatic beta cells, increasing the size and number of cells in the islets of Langerhans, stimulation of insulin secretion, stimulation of glycogenesis and hepatic glycolysis, protective effect on the destruction of the beta cells, improvement in digestion along with reduction in blood sugar and urea, prevention of pathological conversion of starch to glucose, inhibition of$$
\text { ler }
$$

\section{EF F ECT OF KKS ON WATER C ONS UMP TION}

75

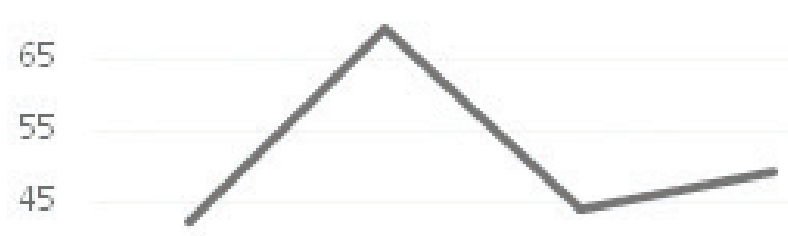

35

Figure 2 and 3: Represents the effect of food and water intake in all the individual groups throughout the study 
$\beta$-galactocidase and $\alpha$-glucocidase, cortisol lowering activities, preserve ß- cell function, prevent diabetes induced ROS formation or Inhibition of alpha-amylase etc. ${ }^{13}$ More scientific and molecular level approaches are necessary to conform the mechanism of action of the formulation.

Throughout the study, the animals treated with the indegeniously prepared polyherbal formulation, KKS did not show any behavioral changes and mortality, however a detailed liver function test, Hematological study and histopathological studies should be conducted to ascertain the risk.

\section{ACKNOWLEDGEMENT}

The authors are thankful to all the teaching and non teaching staffs of the Department of Pharmacology, RVS College of Pharmaceutical Sciences, Coimbatore, Tamil Nadu and Origin Clinical Laboratories, Coimbatore.

\section{CONFLICT OF INTEREST}

All authors have none to declare.

\section{ABBREVIATIONS USED}

KKS: Kathakakhadiradi kashyam; ROS: Reactice oxygen species.

\section{ABOUT AUTHORS}

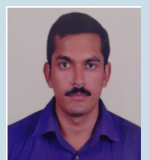

Mr. Abdul Azez: Completed M PHARM in Pharmacology at RVS College of Pharmaceutical sciences- Dr MGR medical university Chennai and currently working as a clinical pharmacist at a tertiary care hospital. Has published many scientific articles both in international and nationa journals. Has presented scientific papers and presentations in different scientific conferences nationally. Research areas of interest are: preclinical studies, herbal drug developments and molecular studies.

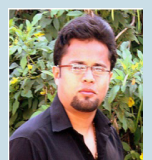

Mr. Shawn Tomy: Completed Doctor of Pharmacy provisionally from The Tamilnadu Dr MGR Medical University and has completed Bachelor degree in social work from Barathiyar University. Currently working as an intern at KG Hospital and Postgraduate Research Institute.. Has published many scientific articles both in international and national journals. Has presented scientific papers and presentations in different scientific conferences nationally. Research areas of interest are: clinical studies on diabetes, Educational and its impact over disease management, Cardiovascular disorders and their future risk etc.

\section{REFERENCES}

1. Petchi RR, Vijaya C, Parasuraman S. Antidiabetic Activity of Polyherbal Formulation in Streptozotocin-Nicotinamide Induced Diabetic Wistar Rats. J Tradit Complement Med. 2014;4(2):108-17

2. Parasuraman S, Thing GS, Dhanaraj SA. Polyherbal formulation: Concept of Ayurveda. Pharmacogn Rev. 2014;8(16):73-80.

3. Kumar $\mathrm{CH}$, Kumar JNS, Ishaq BM, Rani GU, Prkash KV. Antidiabetic activity of a polyherbal preparation. Pharmacologyonline. 2010;2(1):780-87.

4. Grover JK, Yadav S, Vats V. Medicinal plants of India with anti-diabetic potential. J Ethnopharmacol. 2002;81(1):81-100.

5. P Daisy, Feril G, Kani J. Evaluation of antidiabetic activity of various extracts of Cassia auriculata linn. bark on streptozotocin-induced diabetic wistar rats. Int J Pharm Pharm Sci. 2012;4(4):312-18.

6. Tomy S, Chander SJU, Celine S, Ujwala TK, Kandasamy CS, Arulraj P, et al. Antidiabetic effect of polyherbal formulation in OGTT and streptozotocin induced diabetic rat model. Int J Pharm Sci. 2015;7(10):216-19.

7. Akbarzadeh A, Norouzian D, Mehrabi MR, Jamshidi SH, Farhangi A, Verdi AA, et al. Induction of diabetes by streptozotocin in rats. Indian J Clin Biochem. 2007;22(2):60-4
8. Ashok BK, Bhat DS, Ravishankar B. Screening of intestinal transit time of Euphorbia fusiformis Bunch.- Ham. ex D. Don in swiss albino mice. Indian J Nat Prod Resour. 2012;3(4):547-50.

9. Parasuraman S, Raveendran R, Kesavan R. Blood sample collection in small laboratory animals. J Pharmacol Pharmacother. 2010;1(2):87-93.

10. Lanjhiyana S, Garabadu D, Ahirwar D, Bigoniya P, Rana AC, Patra KC, et al. Antidiabetic activity of methanolic extract of stem bark of Elaeodendron glaucum Pers. in alloxanized rat model. Adv Appl Sci Res. 2011;2(1):47-62.

11. Azeez A, Ali Abdalla FM, Tomy S, Suresh R, Johnson B. Pharmocognostic and phytochemical evaluation of polyherbal formulation Kathakakhadiradi Kashyam. Int J Pharm Sci Rev Res. 2016;37(1):96-100.

12. Han X, Karpakka J, Kainulainen H, TakalaTES. Effects of streptozotocin-induced diabetes, physical training and their combination on collagen biosynthesis in rat skeletal muscle. Acta Physiol. 2008;155(1):9-16.

13. Sinha D, Dwivedi C, Dewangan MK, Yadav R, Rao SP, Chandrakar K, et al. Ant diabetic potential of herbal plants and polyherbal formulation. Int J Phytother Res. 2014:4(3):28-49. 